\title{
Antioxidant Effects of Green Tea Leaf Extract on Chemical properties of Corn Refined Oil of Microwave Fried Potatoes
}

\author{
Masomeh Hoseini ${ }^{1}$, Maryam Fahim Danesh ${ }^{2 *}$ \\ 'Department of Food Science and Technology, Islamic Azad University of Shahr Ghods, Tehran \\ ${ }^{2}$ Faculty of Food Science and Technology, Islamic Azad University of Shahr Ghods, Tehran
}

\section{*Correspondence to Maryam Fahim Danesh Tel: 09302742424 \\ Email: \\ Fahimdanesh78@yahoo.com}

Received January 13, 2018 Accepted May 19, 2018 Published online September 30, 2019

\begin{abstract}
Introduction: Oxygen, light, heat, metal ions, and enzymes are among the agents that oxidize oils, fats, and high-fat food products which result in oxidative spoilage. Due to the toxicity and cancer risk of oxidative agents, the use of synthetic antioxidants is important for delaying the oxidation processes. The purpose of this study was to evaluate the protective effect of natural antioxidants including green tea leaf extract and butylated hydroxytoluene (BHT) on the oxidation of the corn refined oil of microwave-heated fried potatoes.

Methods: To this end, corn refined oil and corn oil were treated with green tea leaf extracts (i.e., $200,400,600$, and $800 \mathrm{ppm}$ ), followed by treating the oils with a combination of green tea leaf extract (600 ppm) and BHT (200 ppm). The samples with no anti-oxidant treatments were used as the controls. Eventually, several parameters related to the corn oils were determined, including peroxide content, acidity, polar compounds, and ionic bond conjugates.

Results: Based on the results, significant increases were observed in peroxide, acidity, polar compounds, and ionic bond conjugates in the corn refined oil of microwave fried potatoes $(P<0.05)$. On the other hand, the results showed that the heating process reduced peroxide content $(P<0.05)$. However, acidity increased significantly during the heating process $(P>0.05)$ and the lowest acid value was observed in the mixture of $600 \mathrm{ppm}$ of the green tea leaf with 200 ppm of the BHT. There was no significant difference between the control group and the samples treated with 200 ppm of the green leaf extract $(P<0.05)$ in terms of polar components. In addition, a significant decrease was found in the conjugated dienes by increasing the green tea leaf extract concentration $(P<0.05)$. Finally, the highest protection was achieved in the oils that were treated with a combination of green tea leaf extract and BHT.

Conclusion: In general, the green tea leaf extract and BHT have antioxidant activities that make them suitable agents for use in food protection industries.

Keywords: Green tea leaf extract, Corn oil, Microwaves, Antioxidant, frying, Butylated hydroxytoluene
\end{abstract}

\section{Introduction}

Please cite this article as follows: Hoseini M, Fahim Danesh M. Antioxidant effects of green tea leaf extract on chemical properties of corn refined oil of microwave fried potatoes. Int J Basic Sci Med. 2019;4(3):96101. doi:10.15171/ ijbms.2019.18.
Oils constitute an important part of the human diet. In addition, oils are subjected to oxidation and deterioration due to the presence of a significant amount of double bonds in these substances, making them unusable in food products if the deterioration exceeds an allowed limit. ${ }^{1}$ Thus, antioxidants are used to prevent lipid oxidation or free radical damages due to oxidation. $^{2}$

Nowadays, consuming high doses of synthetic antioxidants has increased to prevent the carcinogenicity of oxidative substances. ${ }^{3,4}$
Many studies have sought to replace chemicals with natural substances in order to remove or reduce the chemical additives in food products. In this field, several attempts were made to find natural antioxidants. ${ }^{5}$ For example, the effect of synthetic and natural antioxidants on the commercially produced corn oil at frying temperature and found that natural antioxidants has been shown to significantly lowered the rate of oil oxidation during the frying process. ${ }^{6}$ Polyphenols in the green tea leaf are considered as natural antioxidants. Further, Chen et al showed the anti-oxidative efficiency of green tea catechin extract,

(c) 2019 The Author(s); Published by Zabol University of Medical Sciences. This is an open-access article distributed under the terms of the Creative Commons Attribution License (http://creativecommons.org/licenses/by/4.0), which permits unrestricted use, distribution, and reproduction in any medium, provided the original work is properly cited. 
along with butylated hydroxytoluene (BHT) in preventing the canola, lard, and chicken fat oxidation. ${ }^{7}$ BHT, also known as dibutylhydroxytoluene, is a lipophilic organic compound and a chemical derivative of phenol, which presents antioxidant properties. ${ }^{8}$

Corn oil contains essential fatty acids, vitamins $\mathrm{K}$ and E, as well as high amounts of unsaturated fatty acids and small amounts of saturated fatty acids, respectively. Furthermore, this oil is rich in phytosterols (plant sterols) and can lower cholesterol absorption by $>25 \%$ and thus reduce the risk of cardiovascular diseases. ${ }^{9}$ Studies regarding the effects of the corn oil on physical growth and blood lipid demonstrated that mice fed with corn oil had higher high-density cholesterol and lower low-density cholesterol levels. ${ }^{9}$ Accordingly, the use of synthetic antioxidants to delay the oxidation processes in foods is important due to the toxicity and cancer risk of oxidative agents. Therefore, this research was conducted to evaluate the antioxidant capacity of the green tea leaf extract in the stability of the refined corn oil.

\section{Materials and Methods}

Preparation of Green Tea Leaf Extract

The green tea leaves were obtained from Karaj Seed and Seedlings Institute (Karaj, Allameh Jafari Boulevard). The leaves were spliced from the stem and dried using a dry air stream and then powdered as well. Moreover, the leaves were shredded in a mixer and then, $100 \mathrm{~mL}$ of water was added to $25 \mathrm{~g}$ of the sample, and they were placed at $45-30^{\circ} \mathrm{C}$ for one hour. Next, the samples were filtered by a filter paper and the extracts were purified by $80 \%$ dichloromethane solution, followed by isolating the solvent using a rotary machine. After solvent isolation, a concentrated extract remained in the bottom of the container as described by Sharifi et al. ${ }^{10}$ The refined corn oil and BHT were obtained from Oila Company (Tehran province, Tehran, Argentina Square) and SoroShimi Company (Tehran, Iran), respectively.

\section{Treatments}

The corn oils were treated with different concentrations of green tea leaf extracts (i.e., 200, 400, 600, and 800 ppm). Additionally, the synergetic effects of the tea extract and BHT were assessed by treating the oil with $600 \mathrm{ppm}$ of the tea extract and $200 \mathrm{ppm}$ of the BHT. The control group received no treatment. In addition, $300 \mathrm{cc}$ volume of oil was added to potatoes immediately before the heating process.

\section{Protective Assays}

The changes in peroxide content, ${ }^{11}$ the acidity, ${ }^{12}$ polar compounds, ${ }^{13}$ and dual conjugated dienes were examined in this step. ${ }^{14}$ All examinations were done in triplicate according to the National Standard of Iran (No. 1375.4179) for measuring the peroxide count in the oil, ${ }^{11}$ the National Standard of Iran No 1377.4178 for measuring acidity in the oil and eaten fats, ${ }^{12}$ the National Standard of Iran No 1377.4078 for measuring polar products in the oil and eaten fats, ${ }^{13}$ and the National Standard of Iran No 1375.3734 for measuring the stability of the oil. ${ }^{15}$ Finally, the dual conjugated dienes were measured according to Saguy et al. ${ }^{14}$

\section{Statistical Analysis}

The Statistical Analysis System, version 9.1 was used to analyze the data, followed by utilizing Duncan's multiplerange test to compare the means.

\section{Results}

Evaluation of Peroxide Level

The results of peroxide content before and 10 minutes after heating are shown in Table 1. Although there were no significant differences regarding the peroxide values between the groups before heating (Figure 1A), the highest protective role against peroxidation was observed in 600 ppm GTE + 200 ppm BHT group at 10 minutes after heating (Figure 1B).

\section{Changes in Acidity}

Based on the data on the acidity of the corn oil in Figures $2 \mathrm{~A}$ and $2 \mathrm{~B}$, no significant difference was found in the acid value by increasing the green tea leaf before heating $(P>0.05)$ while a significant reduction was found in this value after the heating process $(P>0.05)$. The acidity value increased significantly during the heating process $(P>0.05)$, indicating an increase in the oil deterioration during the frying process. The lowest acid value was observed in the mixture of $600 \mathrm{ppm}$ of the green tea leaf

Table 1. Peroxide Content (milliequivalent (mEq) of oxygen) in the Corn Oil Before and 10 Minutes After Microwave Heating

\begin{tabular}{lcc}
\hline Groups & $\begin{array}{c}\text { Peroxide Value Before Microwave Heating } \\
\text { Process }(\text { Mean } \pm \text { SD) }(\mathbf{m E q})\end{array}$ & $\begin{array}{c}\text { Peroxide Value After Microwave Heating } \\
\text { Process }(\text { Mean } \pm \text { SD) }(\mathbf{m E q})\end{array}$ \\
\hline Control (no treatment) & $0.14 \pm 0.01$ & $5.8 \pm 0.5$ \\
200 ppm GTE & $0.13 \pm 0.02$ & $5.5 \pm 0.35$ \\
400 ppm GTE & $0.12 \pm 0.05$ & $5.4 \pm 0.4$ \\
600 ppm GTE & $0.11 \pm 0.05$ & $3.1 \pm 0.55$ \\
800 ppm GTE & $0.10 \pm 0.02$ & $3.0 \pm 0.5$ \\
200 ppm BHT & $0.11 \pm 0.01$ & $3.4 \pm 0.4$ \\
600 ppm GTE +200 ppm BHT & $0.088 \pm 0.01$ & $<0.05$ \\
\hline
\end{tabular}

Abbreviations: GTE: green tea extract; BHT: Butylated hydroxytoluene; SD: Standard deviation. 

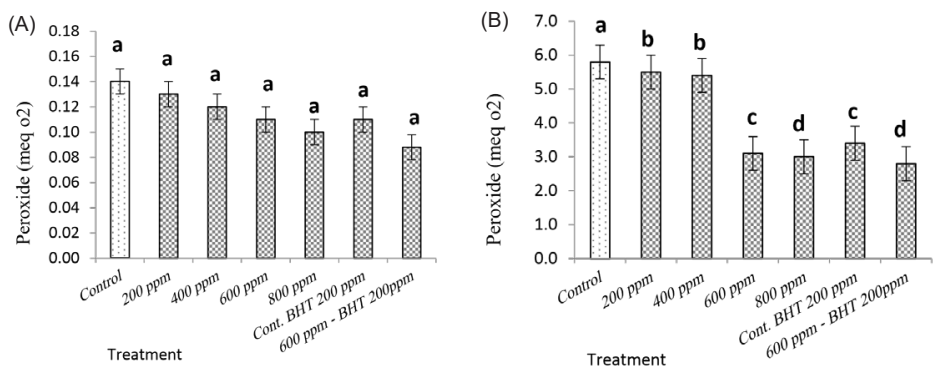

Figure 1. Between-group Analyses for Peroxide Values (milliequivalent (mEq) of oxygen) in the Corn Oil Before (A) and 10 Minutes After (B) Microwave Heating Process.
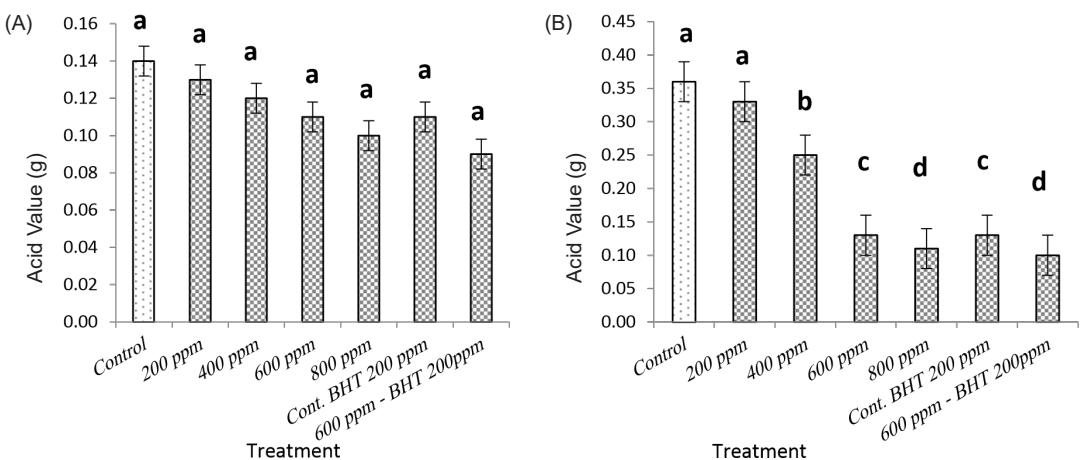

Figure 2. Result of Acid Value in the Corn Oil Before (A) and 10 Minutes After (B) Microwave Heating Process. Note. The significant difference was demonstrated as letters $\mathrm{a}, \mathrm{b}, \mathrm{c}$, and $\mathrm{d}(P<0.05)$.

with 200 ppm of BHT. The results are provided in Table 2.

Alternations in the Polar Compounds

As shown in Figure 3, there was no significant difference regarding polar components between the control group and the sample treated with $200 \mathrm{ppm}$ of the green leaf extract $(P<0.05)$. The polar compound value decreased significantly by increasing the green leaf extract concentration $(P<0.05)$. The lowest polar compound value was reported in the sample containing $800 \mathrm{ppm}$ of the green leaf extract and the mixture of $600 \mathrm{ppm}$ of the green tea extract with $200 \mathrm{ppm}$ of the BHT (Table 3).

Double Bond Changes in the Corn Oil

As shown in Figure 4, a significant decrease was observed in the conjugated dienes of the corn oil by increasing the green tea leaf extract before and after the microwave heating process $(P<0.05)$. In comparison with two treatments, conjugated dienes increased significantly during the heating process $(P<0.05)$, the details of which are presented in Table 4.

\section{Discussion}

The results showed that the heating process reduced all the mentioned parameters including peroxide, acidity, polar compounds, and the ionic bond conjugates of the corn oil. The highest protection was achieved in the oils treated with a combination of the green tea leaf extract and BHT.

Peroxide is the product of lipid oxidation. Generally, the oils with higher free fatty acid (FFA) content are more vulnerable to oxidation. In addition, various changes

Table 2. Acidity of the Corn Oil Before and Ten Minutes After Microwave Heating Process

\begin{tabular}{lcc}
\hline Groups & $\begin{array}{c}\text { Acidity Value Before Microwave Heating } \\
\text { Process (Mean } \pm \text { SD) }(\mathbf{g})\end{array}$ & $\begin{array}{c}\text { Acidity Value After Microwave Heating } \\
\text { Process (Mean } \pm \text { SD) }(\mathbf{g})\end{array}$ \\
\hline Control & $0.14 \pm 0.01$ & $0.36 \pm 0.033$ \\
200 ppm GTE & $0.13 \pm 0.01$ & $0.33 \pm 0.03$ \\
400 ppm GTE & $0.12 \pm 0.02$ & $0.25 \pm 0.02$ \\
600 ppm GTE & $0.11 \pm 0.01$ & $0.13 \pm 0.03$ \\
800 ppm GTE & $0.10 \pm 0.01$ & $0.11 \pm 0.035$ \\
200 ppm BHT & $0.11 \pm 0.01$ & $0.14 \pm 0.4$ \\
600 ppm GTE +200 ppm BHT & $0.1 \pm 0.02$ & $0.13 \pm 0.04$ \\
\hline
\end{tabular}

Abbreviations: GTE: green tea extract; BHT: Butylated hydroxytoluene; SD: Standard deviation. 

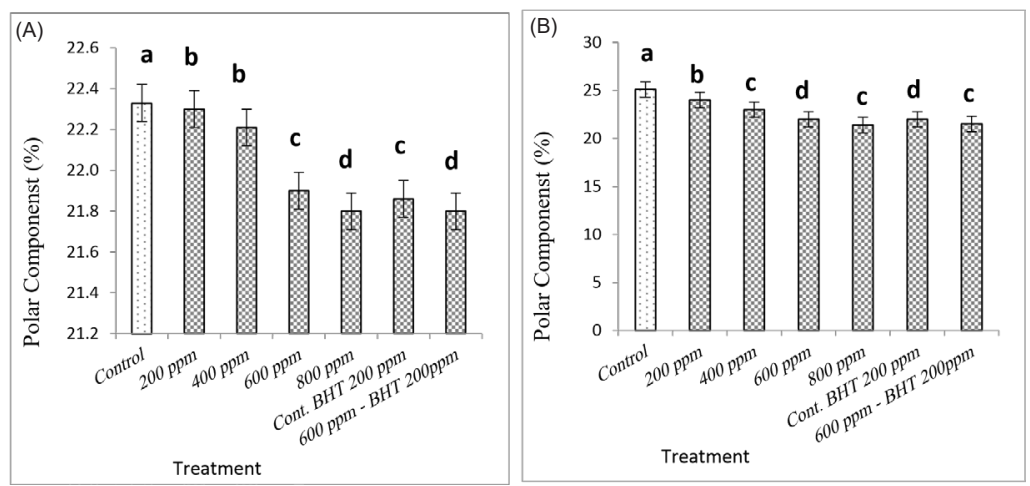

Figure 3. Polar Components (Percentage) in the Corn Oil Before (A) and 10 Minutes After (B) Microwave Heating Process. Note. The significant difference was denoted as letters $\mathrm{a}, \mathrm{b}, \mathrm{c}$, and $\mathrm{d}(P<0.05)$.

Table 3. Polar Compounds (Percentage) in the Corn Oil Before and 10 Minutes After Microwave Heating

\begin{tabular}{|c|c|c|c|}
\hline Groups & $\begin{array}{l}\text { Acidity Value Before Microwave Heating Process } \\
(\text { Mean } \pm \text { SD) }(\mathrm{g})\end{array}$ & $\begin{array}{l}\text { Acidity Value After Microwave Heating } \\
\text { Process }(\text { Mean } \pm \text { SD) }(\mathrm{g})\end{array}$ & $P$ Value \\
\hline Control & $22.33 \pm 0.09$ & $25.1 \pm 0.8$ & $<0.05$ \\
\hline 200 ppm GTE & $22.3 \pm 0.09$ & $24 \pm 0.5$ & $<0.05$ \\
\hline 400 ppm GTE & $22.21 \pm 0.09$ & $23 \pm 0.5$ & $<0.05$ \\
\hline 600 ppm GTE & $21.90 \pm 0.07$ & $22 \pm 0.6$ & $<0.05$ \\
\hline 800 ppm GTE & $21.80 \pm 0.09$ & $21.4 \pm 0.8$ & $<0.05$ \\
\hline 200 ppm BHT & $21.90 \pm 0.07$ & $22 \pm 0.6$ & $<0.05$ \\
\hline 600 ppm GTE + 200 ppm BHT & $21.86 \pm 0.08$ & $22 \pm 0.7$ & $<0.05$ \\
\hline
\end{tabular}

Abbreviations: GTE: green tea extract; BHT: Butylated hydroxytoluene; SD: Standard deviation.

occur in the oils and fats when the peroxide value reaches a certain threshold. For example, aldehyde and columnar substances, as well as short-chain fatty acids (as the secondary and tertiary products) may be formed contributing to the changes in the odor and taste of fatty substances. ${ }^{16}$ Clearly, green tea extract is a natural antioxidant that reduces hydroperoxides formation by inhibiting free radicals. ${ }^{17}$

Kaviani et al evaluated the discarding time of the canola oil during 40-hour potato frying in different conditions at temperatures of 150,165 , and $180^{\circ} \mathrm{C}$ and the concentration of 0,50 , and $100 \mathrm{mg} / \mathrm{L}$ of tert-butylhydroquinone (TBHQ) antioxidant based on the oxidative index. The results indicated that the canola oil reached a maximum peroxide value at $150^{\circ} \mathrm{C} .1^{17}$

In a study regarding the effect of the heating process on the chemical properties of the vegetable oils, has been reported that substantial changes in the peroxide value due to peroxide decomposition and reformation. The acid value and total polar compounds in the oils were increased during frying. ${ }^{18}$

Likewise, the increased oil deterioration during the frying process and the oil spillage results in the elevation of the FFA content of the oils. ${ }^{19}$ Further, FFA content increases by an increase in the heating time due to triglycerides hydrolyzing. The addition of antioxidants
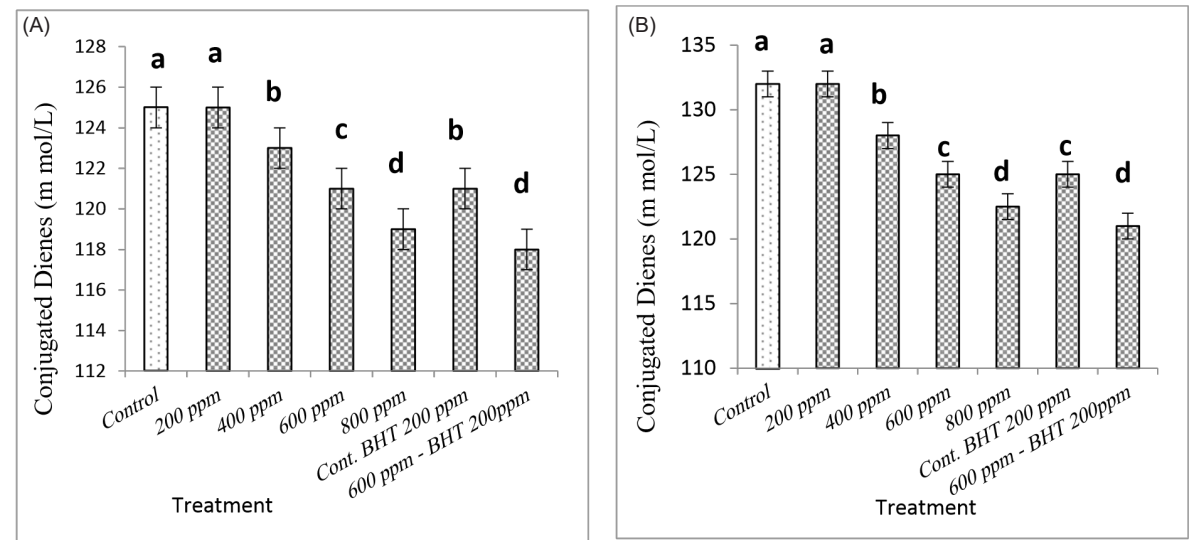

Figure 4. Conjugated Dienes (mmol/L) in Corn Oil Before $(\mathrm{A})$ and 10 Minutes After $(\mathrm{B})$ the Microwave Heating Process. Note. The significant difference was denoted as letters $\mathrm{a}, \mathrm{b}, \mathrm{c}$, and $\mathrm{d}(P<0.05)$. 
Table 4. Result of Conjugated Dienes (mmol/L) in the Corn Before and Ten Minutes After Microwave Heating

\begin{tabular}{|c|c|c|c|}
\hline Groups & $\begin{array}{l}\text { Conjugated Before Microwave Heating } \\
\text { Process }(\text { Mean } \pm \text { SD) }(\mathrm{g})\end{array}$ & $\begin{array}{l}\text { Conjugated After Microwave Heating } \\
\text { Process }(\text { Mean } \pm \text { SD) }(g)\end{array}$ & P Value \\
\hline Control & $125 \pm 1.00$ & $132 \pm 1.00$ & $<0.05$ \\
\hline 200 ppm GTE & $125 \pm 1.00$ & $132 \pm 1.00$ & $<0.05$ \\
\hline 400 ppm GTE & $123 \pm 0.8$ & $128 \pm 1.00$ & $<0.05$ \\
\hline 600 ppm GTE & $121 \pm 1.00$ & $125 \pm 1.00$ & $<0.05$ \\
\hline 800 ppm GTE & $119 \pm 0.95$ & $122.5 \pm 1.00$ & $<0.05$ \\
\hline 200 ppm BHT & $123 \pm 0.8$ & $125 \pm 1.00$ & $<0.05$ \\
\hline 600 ppm GTE + 200 ppm BHT & $121 \pm 1.00$ & $125 \pm 1.00$ & $<0.05$ \\
\hline
\end{tabular}

Abbreviations: GTE: green tea extract; BHT: Butylated hydroxytoluene; SD: Standard deviation.

reduces the hydrolysis of the oils and thus decreases the acid value. ${ }^{20}$

Similarly, polar compounds are formed in the fried oil by the decomposition and oxidation of polymeric and circular substances during a deep frying process. ${ }^{21}$ Kaviani et al concluded that polarity has a direct connection with the temperature of the oils. ${ }^{17}$ The maximum allowed threshold for polar compounds (including triglycerides, FFA, and polymeric derivative) is considered $25 \% .^{22}$

Furthermore, conjugated dienes represent the initial stages of oxidative changes under frying conditions. In this study, treatment with BHT and green tea leaf extract significantly inhibited the formation of polar compounds and chemical bonds. It should be noted the minimum polar compounds was observed in the mixture of $600 \mathrm{ppm}$ of green leaf extracts with $200 \mathrm{ppm}$ of BHT, as well as 800 ppm of the green leaf extract. Moreover, Kaviani et al showed that increased frying temperature was significantly associated with the increased formation of conjugated dienes. ${ }^{17}$ These results are consistent with our findings and those of Sharayei et al. ${ }^{23}$ The results of Farhoosh and Tavassoli-Kafrani also indicated increased conjugated dienes by $481 \%$ after 32 hours in the sunflower oil without antioxidant while the content of dienes reduced to $93 \%$ in the oil containing $100 \mathrm{~mL}$ of TBHQ synthetic antioxidants. ${ }^{24}$

The results of the present study revealed that the green tea leaf extract and BHT reduced the oxidant content of the refined corn oil 10 minutes after heating. The antioxidant activity of green tea polyphenols is primarily attributed to the combination of aromatic rings and hydroxyl groups. Additionally, these groups bind and neutralize lipid free radicals by binding to their hydroxyl groups. Numerous studies demonstrated that polyphenols and tea catechins are considered as potent electron donors and effective scavengers of reactive oxygen species including superoxide anions peroxyl radicals, and singlet oxygen in vitro. ${ }^{11,25,26}$ Aladedunye indicated that a number of underexploited sources of natural antioxidants could be used to improve the stability of the frying oils. ${ }^{27}$ Mir-Ahmadi et al showed that the antioxidant effect of green tea extract at 200 and $500 \mathrm{ppm}$ concentrations was better than that of other antioxidants. In addition, the combination of green tea extract with BHT demonstrated antagonistic effect but no remarkable synergism. ${ }^{28}$ According to the study by Farhoosh and Tavassoli-Kafrani, the sunflower oil represented less stability (25.4 hours) than the oil containing $100 \mathrm{mg}$ of TBHQ (32.1 hours) given the maximum polar compounds of $25 \%$ (23). The antioxidant activity of green tea extract has been previously shown. ${ }^{29}$

\section{Conclusion}

Based on the results of the present study, the green tea leaf extract can be used as an alternative synthetic antioxidant in the formulation of edible oils. It is worth mentioning that the addition of natural antioxidants to the oils should be performed based on national and international standards.

\section{Ethical Approval \\ Not applicable.}

\section{Competing Interest}

We declare that we have no conflicts of interest.

\section{Acknowledgements}

This research was partially supported by the Islamic Azad University of Shahr Ghods, Tehran, Iran. We would like to thank all the people and colleagues who helped us with this project.

\section{References}

1. Goodarzi S, Rafiei S, Javadi M, Khadem Haghighian H, Noroozi S. A review on antioxidants and their health effects. Journal of Nutrition and Food Security. 2018;3(2):106-12.

2. Amini B, Keramat J, Hojjatoleslamy M, Jahadi M, Mahmoudian M. Evaluation of the Antioxidant Activity of the Essential Oil of Satureja hortensis on the Stability of Colza and Anchovy Oil. Journal of Food Technology and Nutrition. 2015;12(3):29-38.

3. Fan W, Sun J, Chen Y, Qiu J, Zhang Y, Chi Y. Effects of chitosan coating on quality and shelf life of silver carp during frozen storage. Food Chem. 2009;115(1):66-70. doi:10.1016/j.foodchem.2008.11.060

4. Hosseini MH, Razavi SH, Mousavi MA. Antimicrobial, physical and mechanical properties of chitosan-based films incorporated with thyme, clove and cinnamon essential oils. J Food Process Preserv. 2009;33(6):727-743. doi:10.1111/j.1745-4549.2008.00307.x 
5. Suhaj M. Spice antioxidants isolation and their antiradical activity: a review. J Food Compost Anal. 2006;19(6-7):531537. doi:10.1016/j.jfca.2004.11.005

6. Jin W. Repressions of the toxic $\alpha, \beta$-hydroxyaldehyde homologues, HHE, HOE, HNE and HDE formations by synthetic and natural antioxidants in commercial corn oil at frying temperature [thesis]. Minnesota: University of Minnesota; 2015.

7. Chen ZY, Wang LY, Chan PT, Zhang Z, Chung HY, Liang C. Antioxidative activity of green tea catechin extract compared with that of rosemary extract. J Am Oil Chem Soc. 1998;75(12):1141-1145. doi:10.1007/s11746-9980303-5

8. Yehye WA, Rahman NA, Ariffin A, et al. Understanding the chemistry behind the antioxidant activities of butylated hydroxytoluene (BHT): a review. Eur J Med Chem. 2015;101:295-312. doi:10.1016/j.ejmech.2015.06.026

9. Shariati M, Khaksary Haddad M, Jafari H, Rezaeizadeh A, Bahadoran M. Effect of dietary fish oil and corn oil on blood biochemical factors in diabetic Rat. Iran South Med J. 2005;8(1):8-14. [Persian].

10. Miri A, Sharifi Rad J, Hoseini Alfatemi SM, Sharifi Rad M. A study of Antibacterial potentiality of some plants extracts against multidrug resistant human pathogens. Ann Biol Res. 2013;4(8):35-41.

11. Guo Q, Zhao B, Shen S, Hou J, Hu J, Xin W. ESR study on the structure-antioxidant activity relationship of tea catechins and their epimers. Biochim Biophys Acta. 1999;1427(1):13-23. doi:10.1016/s0304-4165(98)00168-8

12. National Standard of Iran No 1377.4178. Measuring acidity in Oil and eaten fats.

13. Rao SS. Biofeedback therapy for constipation in adults. Best Pract Res Clin Gastroenterol. 2011;25(1):159-166. doi:10.1016/j.bpg.2011.01.004

14. Saguy IS, Shani A, Weinberg P, Garti N. Utilization of Jojoba Oil for Deep-fat Frying of Foods. LWT - Food Sci Technol. 1996;29(5-6):573-577. doi:10.1006/fstl.1996.0088

15. Basilisco G, Coletta M. Chronic constipation: a critical review. Dig Liver Dis. 2013;45(11):886-893. doi:10.1016/j. dld.2013.03.016

16. AOCS Official Method Cc 13e-92. https://www.aocs. org/attain-lab-services/methods/methods/methoddetail? productId=111500. Published 2017.

17. Kaviani M, Niazmand R, Shahidi Noghabi M. Discarding time evaluation of canola oil based on oxidation indexes during potato deep frying. Journal of Research and Innovation in Food Science and Technology. 2013;2(1):37-
50. [Persian].

18. Mishra R, Sharma HK. Effect of frying conditions on the physico-chemical properties of rice bran oil and its blended oil. J Food Sci Technol. 2014;51(6):1076-84. doi: 10.1007/ s13197-011-0602-y.

19. Kalapathy U, Proctor A. A new method for free fatty acid reduction in frying oil using silicate films produced from rice hull ash. J Am Oil Chem Soc. 2000;77(6):593-598. doi:10.1007/s11746-000-0095-4

20. Moghimi M, Farzaneh V, Bakhshabadi H. The effect of ultrasound pretreatment on some selected physicochemical properties of black cumin (Nigella sativa). Nutrire. 2018;43(1):18.

21. Fazel $M$, Omidbeygi $M$, Barzegar $M$, Naghdi Badi $H$. Influence of heating on antiradical activity of essential oils of thyme, summer savory and clove by 2, 2-diphenyl1-picrylhydrazyl (DPPH) method. Journal of Medicinal Plants. 2007;2(22):54-63. [Persian].

22. El-Anany AM. Antioxidative effect of tea extracts on oxidation of soybean oil during deep-fat frying process. Adv. Food Sci. 2013;35(4):181-189.

23. Sharayei P, Farhoosh R, Poorazrang H, Khodaparast MHH. Improvement of canola oil frying stability by bene kernel oil's unsaponifiable matter. J Am Oil Chem Soc. 2011;88(7):993-1000. doi:10.1007/s11746-011-1764-5

24. Farhoosh R, Tavassoli-Kafrani MH. Simultaneous monitoring of the conventional qualitative indicators during frying of sunflower oil. Food Chem. 2011;125(1):209-213. doi:10.1016/j.foodchem.2010.08.064

25. Nakagawa T, Yokozawa T. Direct scavenging of nitric oxide and superoxide by green tea. Food Chem Toxicol. 2002;40(12):1745-1750. doi:10.1016/s02786915(02)00169-2

26. Babu PV, Liu D. Green tea catechins and cardiovascular health: an update. Curr Med Chem. 2008;15(18):18401850. doi:10.2174/092986708785132979

27. Aladedunye FA. Natural antioxidants as stabilizers of frying oils. Eur J Lipid Sci Technol. 2014;116(6):688-706. doi:10.1002/ejlt.201300267

28. Mir-Ahmadi F, Fatemi H, Sahari MA. Effect of green Tea extract on the inhibition of sunflower oil oxidation. Food Science and Technology. 2005;2(4):61-70. [Persian].

29. Mildner-Szkudlarz S, Zawirska-Wojtasiak R, Obuchowski W, Gośliński M. Evaluation of antioxidant activity of green tea extract and its effect on the biscuits lipid fraction oxidative stability. J Food Sci. 2009;74(8):S362-70. 